\title{
Growth of fishes, crustaceans and molluscs: estimation of the von Bertalanffy, Logistic, Gompertz and Richards curves and a new growth model
}

\author{
Alfredo Hernandez-Llamas ${ }^{1, *}$, David A. Ratkowsky ${ }^{2}$ \\ ${ }^{1}$ Centro de Investigaciones Biológicas del Noroeste (CIBNOR), Apdo. Postal 128, La Paz, B.C.S. 23000, Mexico \\ ${ }^{2}$ School of Agricultural Science, University of Tasmania, Private Bag 54, Hobart, Tasmania 7001, Australia
}

\begin{abstract}
A total of 16 data sets on wild and cultivated fishes, crustaceans and molluscs were used to test and compare conventional growth curves (von Bertalanffy, Logistic, Gompertz and Richards) and a new growth model. Statistical properties for estimation of the models were evaluated and compared to determine suitability. The absolute value of the Hougaard measure of skewness of parameter estimates (h) was used as the criterion to evaluate statistical behavior of the models. For conventional curves, the cases where the estimates were severely skewed or contained considerable nonlinearity $(h>0.15)$ were: von Bertalanffy $(93.5 \%)$, Logistic $(87.5 \%)$, Gompertz $(85.1 \%)$ and Richards (97.6\%). Depending on the parameterization used in the new model, 87.5 to $91.6 \%$ had negligible skewness $(h \leq 0.1)$, indicating desirable close-to-linear behavior and better performance than conventional growth curves. The poor statistical properties for estimation of conventional growth curves call for a critical reconsideration of their indiscriminate use to model growth of fishes, crustaceans and molluscs. The new model can be reliably used to analyze growth of organisms under a wide variety of situations and to derive statistical inferences of possible relations of its parameters with ecological or management variables.
\end{abstract}

KEY WORDS: Growth modeling $\cdot$ von Bertalanffy $\cdot$ Logistic $\cdot$ Gompertz $\cdot$ Richards

\section{INTRODUCTION}

Modeling growth of fishes, crustaceans and molluscs has received considerable attention in studies of population dynamics and management of wild and cultivated species. Commonly used curves to study growth, when measured by weight, are the von Bertalanffy, Logistic, Gompertz and Richards. Little emphasis has been placed on the statistical properties of these conventional nonlinear models.

If the parameters of a regression model are all linear, as in the 'straight-line' model or a multiple linear regression model, the least-squares estimators of those parameters are unbiased, normally distributed and achieve the minimum possible variance defined by the so-called 'minimum variance bound'. Such properties are generally agreed to be the most desirable properties that an estimator can possess. However, if the regression model has at least one nonlinear parameter, these properties are not achieved and the leastsquares estimates of all the parameters will be biased, not normally distributed, and may have variances far in excess of the minimum variance bound. In general terms, only when the sample sizes are very large, approaching infinity, can one be certain that the leastsquares estimators will approach these properties. In summary, nonlinear behavior is undesirable because, among other inconveniences, distributions of the estimators of the parameters will not be normally distributed, the estimates and their standards errors will be biased, and this will lead to grossly incorrect inferences (Ratkowsky 1983, 1990).

Comparisons of growth parameters are useful to determine whether differences in growth of a species occur under different ecological conditions. Comparison of parameters of the von Bertalanffy growth curve, 
for example, can be accomplished for different data sets. It must be noted, however, that the parameters $k$ and $L_{\infty}$ of that curve are inversely related, and they must be used jointly when assessing the growth performance of fish (Prein 1993). A convenient and robust tool for the comparison of growth parameters of different data sets is the growth performance index $\phi\left(=\log _{10}\right.$ $\left.k+2 \log _{10} L_{\infty}\right)$ described by Moreau et al. (1985).

Other problems relate to poor estimation properties of asymptotic parameters. For example, Urban (2002) compared the von Bertalanffy, Logistic, Gompertz and Richards curves for modeling different developmental stages of the Caribbean pearl oyster Pinctada imbricata under laboratory and natural conditions, observing that the asymptotic length may be under- or overestimated, therefore lacking biological relevance.

In other cases, estimates of growth parameters may be functionally dependent on specific environmental or management variables, such as temperature or stocking density (Pardy et al. 1983, Sadeh et al. 1986, Hernandez-Llamas et al. 1993). In every circumstance, a statistically well-behaved, close-to-linear growth model is highly desirable.

In this study, the most commonly used curves are reconsidered for modeling growth of fishes, crustaceans and molluscs by evaluating the inconveniences derived from their highly nonlinear behavior and concomitant poor statistical properties for estimation. To overcome such inconveniences, statistical behavior of a new model is presented and compared with the conventional growth curves. This new, nonlinear growth curve is based on an alternate parameterization of the von Bertalanffy equation with a desirable close-to-linear behavior that was developed by Schnute \& Fournier (1980) and Ratkowsky (1986). The parameterization used by those authors, however, is restricted to length data for the analysis of asymptotic curves and is not capable of describing sigmoid-shaped growth curves, as is frequently the case when weight data are studied. Similar to other growth curves, our model is intended for general use, so its advantages are tested on a wide variety of species growing under different environmental conditions. We emphasized the desirable statistical properties for estimation of the model as a basic tool for reliably analyzing growth in relation to distinct ecological or management factors. To compare models, data sets of growth of wild and cultivated marine fishes, crustaceans and molluscs were used. Additionally, data of some cultivated freshwater species were also evaluated.

\section{MATERIALS AND METHODS}

Conventional models. Three 3-parameter models, von Bertalanffy (Pauly 1984), Logistic (Tian et al. 1993,
Urban 2002) and Gompertz (Ratkowsky 1990), and one 4-parameter model, Richards (Ratkowsky 1990) were used for modeling growth.

New model. Ratkowsky (1986) proposed the following close-to-linear model to predict growth by measuring length:

$$
L_{t}=l_{i}+\left(l_{f}-l_{i}\right)\left(1-k^{m-1}\right) /\left(1-k^{n-1}\right)
$$

where $l_{i}$ and $l_{f}$ are the initial and final length of the individuals, $k$ relates to the rate at which $L_{t}$ changes from its initial value to its final value, $n$ is the number of data points and $m$ is time modified according to:

$$
m=1+(n-1)\left(t-t_{i}\right) /\left(t_{f}-t_{i}\right)
$$

where $t_{i}$ and $t_{f}$ are initial and final time. Eq. (1) is a generalization of the parameterization proposed by Schnute \& Fournier (1980), which is only suited for equally-spaced time (age) values, whereas the generalization given for $m$ in Eq. (2) is completely unrestricted.

In Eq. (1), if $l_{i}$ is set equal to 0 and the difference $l_{f}-$ $l_{i}$ is defined as total gain in length $\left(l_{g}\right)$, it is possible to predict net length gain as a function of time $\left(L_{t}\right)$ according to:

$$
L_{t}=l_{g}\left(1-k^{m-1}\right) /\left(1-k^{n-1}\right)
$$

The isometric weight-length relationship (Ricker 1979), on the other hand, enables the prediction of weight $(w)$ as a function of length $(l)$ according to:

$$
w=a l^{3}
$$

where $a$ is an allometric coefficient. The substitution of length in Eq. (4) by net length gain of Eq. (3) allows us to calculate net weight gain $\left(W_{t}\right)$ as:

$$
W_{t}=a l_{g}^{3}\left[\left(1-k^{m-1}\right) /\left(1-k^{n-1}\right)\right]^{3}
$$

By using the weight-length relationship, the total weight gain $\left(w_{g}\right)$ can be calculated as:

$$
w_{g}=a l_{g}^{3}
$$

The substitution of this expression in Eq. (5) results in:

$$
W_{t}=W_{g}\left[\left(1-k^{m-1}\right) /\left(1-k^{n-1}\right)\right]^{3}
$$

where net weight gain is now a function of total weight gain.

To calculate growth in terms of weight $\left(w_{t}\right)$, rather than net weight gain, a parameter estimating the initial weight of the individuals $\left(w_{i}\right)$ can be added to the expression above, as follows:

$$
w_{t}=w_{i}+w_{g}\left[\left(1-k^{m-1}\right) /\left(1-k^{n-1}\right)\right]^{3}
$$

An alternative parameterization of the previous expression is: 


$$
w_{t}=w_{i}+\left(w_{f}-w_{i}\right)\left[\left(1-k^{m-1}\right) /\left(1-k^{n-1}\right)\right]^{3}
$$

where total weight gain is replaced by the difference between final weight $\left(w_{f}\right)$ and initial weight $\left(w_{i}\right)$.

Statistical analysis. The conventional models were statistically evaluated and compared with the parameterizations of the new model (Eqs. 8 \& 9). Data sets describing sigmoid-shaped growth curves from 16 marine and freshwater species were used to test the models. The data sets are representative of wild and cultivated fishes, crustaceans and molluscs (Table 1).

The absolute value of the Hougaard measure of skewness $(h)$ in the estimators of individual parameters of a nonlinear regression model is a direct measure of undesirable nonlinear behavior (Ratkowsky 1990). Recently, Haines et al. (2004) reviewed all previously published measures of nonlinearity in nonlinear regression models and developed a new curvature measure based on kurtosis. They showed that kurtosis and skewness are closely linked and that rules of thumb, leading to similar conclusions, could be developed for either measure to assess the extent of nonlinearity in the estimator of any individual parameter. Since the skewness measure (i.e. Hougaard's) is available in SAS, Version 8.1, whereas the new kurtosis measure is not yet available in a standard statistical package, we chose to use the Hougaard measure to assess nonlinearity.

Using $h$, results were classified for skewness according to the values recommended by Haines et al. (2004), which are: negligible skewness $(h \leq 0.1)$, moderate skewness $(0.1<h \leq 0.15)$ and severe skewness $(h>0.15)$. Parameter correlation, residual sum of squares (RSS) and residual variance (RV) were also used as complementary criteria for model performance. Following Ratkowsky (1990), residual variance was used as a criterion for comparison of models incorporating different numbers of

Table 1. Data sets used to evaluate growth models; n: sample size, t: time period

\begin{tabular}{|c|c|c|}
\hline Data set & Description & Source \\
\hline $\begin{array}{l}\text { BM: Atlantic blue marlin } \\
\text { Makaira nigricans }\end{array}$ & $\begin{array}{l}\text { von Bertalanffy and Gompertz fitted to length and weight data. One } \\
\text { of the fastest growing of all teleosts species }(n=17, t=475 d)\end{array}$ & Prince et al. (1991) \\
\hline $\begin{array}{l}\text { BT: Blacktip shark } \\
\text { Carcharhinus limbatus (female) }\end{array}$ & $\begin{array}{l}\text { Logistic equation fitted to weight data. Possibly distinct populations } \\
\text { in different regions, because of sizes attained and sizes at maturity } \\
(\mathrm{n}=10, \mathrm{t}=10 \mathrm{yr})\end{array}$ & Killam \& Parsons (1989) \\
\hline $\begin{array}{l}\text { TA: Tautog } \\
\text { Tautoga onitis (female) }\end{array}$ & $\begin{array}{l}\text { von Bertalanffy fitted to length data. Long-lived species. Comparison } \\
\text { of growth rates with other reef fishes }(\mathrm{n}=20, \mathrm{t}=21 \mathrm{yr})\end{array}$ & Hostetter \& Munroe (1993) \\
\hline $\begin{array}{l}\text { SD: Atlantic spadefish } \\
\text { Chaetodipterus faber }\end{array}$ & von Bertalanffy curve fitted to length data $(n=7, t=6 \mathrm{yr})$ & Hayse (1989) \\
\hline $\begin{array}{l}\text { Y: Yellowtail } \\
\text { Seriola quinqueradiata }\end{array}$ & Intensive culture in floating cages $(n=8, t=210 \mathrm{~d})$ & Nakada \& Murai (1991) \\
\hline CA: Cachama Colossoma spp. & Semi-intensive culture in floating cages $(n=10, t=313 d)$ & Perez \& Martino 1989 \\
\hline $\begin{array}{l}\text { RS: Redear sunfish } \\
\text { Lepomis microlophas }\end{array}$ & Extensive culture in earthen ponds $(n=7, t=6 y r)$ & Bardach et al. (1972) \\
\hline $\begin{array}{l}\text { T: Tilapia } \\
\text { Oreochromis niloticus }\end{array}$ & Semi-intensive culture in earthen ponds $(n=6, t=140 \mathrm{~d})$ & Green et al. (1989) \\
\hline $\begin{array}{l}\text { SE: Sand eel } \\
\text { Amodytes marinus }\end{array}$ & $\begin{array}{l}\text { No growth model was used. Direct comparison of growth data showed } \\
\text { spatial and temporal variation }(n=7, t=7 \mathrm{yr})\end{array}$ & Bergstad et al. (2002) \\
\hline $\begin{array}{l}\text { BS: Blue shrimp } \\
\text { Litopenaeus stylirostris }\end{array}$ & Intensive commercial culture in lined ponds $(n=33, t=224 d)$ & A. Gonzalez (pers. comm.) \\
\hline $\begin{array}{l}\text { WS: White shrimp } \\
\text { Litopenaeus vannamei }\end{array}$ & Semi-intensive culture in earthen ponds $(\mathrm{n}=14, \mathrm{t}=110 \mathrm{~d})$ & Johns et al. (1981) \\
\hline $\begin{array}{l}\text { RC: Red claw crayfish } \\
\text { Cherax quadricarinatus }\end{array}$ & Experimental culture in laboratory $(n=18, t=423 d)$ & Kiewek (2002) \\
\hline $\begin{array}{l}\text { CS: Catarina scallop } \\
\text { Argopecten ventricosus }\end{array}$ & $\begin{array}{l}\text { Extensive culture in 'nestier' trays. Tests for stocking densities } \\
(\mathrm{n}=5, \mathrm{t}=316 \mathrm{~d})\end{array}$ & J. M. Mazon (pers. comm.) ${ }^{c}$ \\
\hline $\begin{array}{l}\text { RMP: Rainbow mother of pearl } \\
\text { Pteria sterna }\end{array}$ & $\begin{array}{l}\text { Extensive culture in 'nestier' trays. Tests for stocking densities } \\
(\mathrm{n}=13, \mathrm{t}=360 \mathrm{~d})\end{array}$ & $\begin{array}{l}\text { M. Monteforte \& } \mathrm{H} \text {. } \\
\text { Bervera (pers. comm.) }\end{array}$ \\
\hline $\begin{array}{l}\text { LPS: Lion paw scallop Nodipecten } \\
\text { subnodosus }\end{array}$ & $\begin{array}{l}\text { Extensive culture in 'nestier' trays. Tests for stocking densities and } \\
\text { culture sites }(\mathrm{n}=4, \mathrm{t}=232 \mathrm{~d})\end{array}$ & 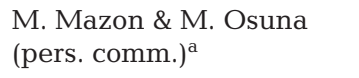 \\
\hline PS: Pen shell Pinna rugosa & $\begin{array}{l}\text { Extensive culture within fens. Tests for stocking densities and } \\
\text { culture sites }(\mathrm{n}=5, \mathrm{t}=245 \mathrm{~d})\end{array}$ & Bojorquez et al. (1987) \\
\hline
\end{tabular}


parameters, in this case, the 4-parameter Richards model versus the 3-parameter models. Prior to analysis, weight data were standardized to lie in the range 0 to 1 . This facilitated the comparison of RSS and RV, and was accomplished by dividing all values of a data set by the highest observed weight in the data set.

The Gauss-Newton and Levenberg-Marquardt nonlinear regression procedures available in SAS 8.01 (SAS Institute) and STATISTICA 6.0 (StatSoft) were used to conduct the statistical analyses. Parameter estimations were carried out using least squares as the loss function.

\section{RESULTS}

Significant results, in terms of regression ANOVA, were obtained in all cases analyzed with the different models $(\mathrm{p}<0.05)$. The growth curves obtained from those regression analyses are presented in Fig. 1 for some of the data sets. All the fitted models were sigmoid-shaped with the exception of the von Bertalanffy, Logistic and Gompertz models for the data set corresponding to red claw crayfish Cherax quadricarinatus (Fig. 1b). Residual values from the regression

Black tip shark
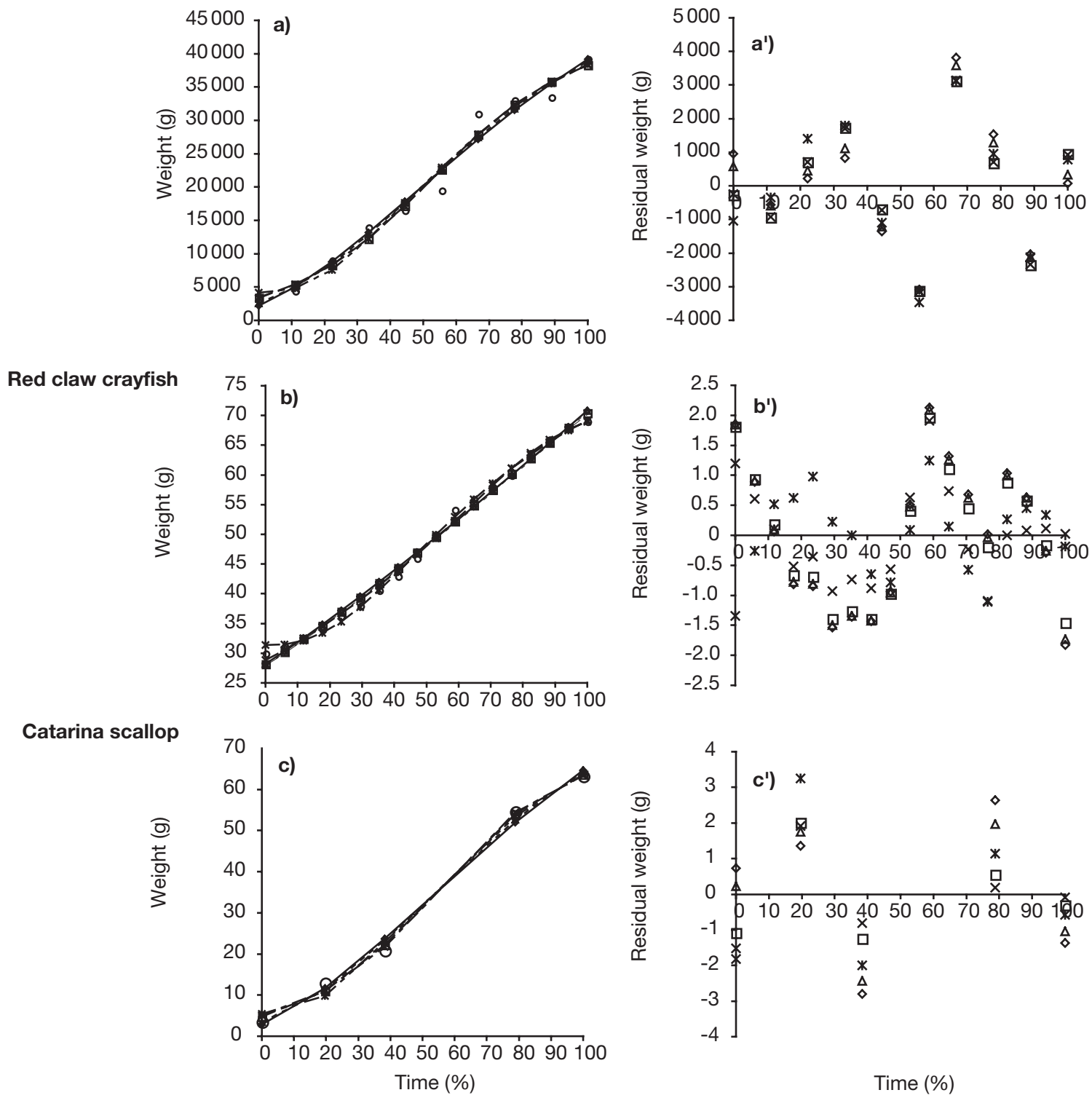

Fig. 1. Fitted growth curves and corresponding residual values using the different models for data corresponding to (a, $\left.\mathrm{a}^{\prime}\right)$ black tip shark, $\left(b, b^{\prime}\right)$ juvenile red claw crayfish and $\left(c, c^{\prime}\right)$ catarina scallop. von Bertalanffy $(\diamond)$, Logistic $(\square)$, Gompertz $(\Delta)$, Richards $(\times)$, Eqs. (8) \& (9) (*) and observed data (O). A common curve for each species is used for Eqs. (8) \& (9) because they gave the same results. The time period analyzed for each species was standardized (percentage) to facilitate representation 
analysis showed the same pattern of behavior for all models, i.e. data points having large residuals for one model tended to have large residuals for all other models.

The growth curves obtained using Eqs. (8) \& (9) are presented in Fig. 2 for all the data sets. Although scarcely discernible, the curve corresponding to blue marlin exhibited an inflection point after $75 \%$ of the period.

The $h$ values obtained for the parameters in the models and data sets are presented in Table 2 . The models where the statistical software was unable to compute $h$ values for at least one of the parameters were von Bertalanffy (2 cases), Gompertz (1 case) and Richards (8 cases). Behavior of parameters depended on the model used, rather than on species or group of species. Larger $h$ values were observed for the data set with the smallest sample size (lion paw scallop, $\mathrm{n}=4$ ) in all models. In the Richards model, regression analysis was not possible because of the small sample size.

The conventional models showed clear nonlinear behavior. Parameter estimation for the von Bertalanffy curve resulted in $93.5 \%$ (43 of 46 estimates) being severely skewed $(h>0.15)$. The Logistic model had $87.5 \%$ (42 of 48 estimates) and the Gompertz model had $85.1 \%$ (40 of 47 estimates) within the same category. The Richards model exhibited the worst performance, $97.6 \%$ (42 of 43 estimates). For species where complete sets of parameters were computed, asymptotic weight $\left(w_{\infty}\right)$ was the parameter most frequently appearing with severe skewness, with $100 \%$ of its estimates in the von Bertalanffy, Logistic and Gompertz models and all but one of the estimates in the Richards model having $h>0.15$.

Eqs. (8) \& (9) clearly showed statistical advantages since $h$ values were lower than those observed in the conventional models (Table 2). Negligible skewness $(h \leq 0.1)$ was observed in 44 of 48 parameter estimates (91.6\%) for Eq. (8) and in 42 of 48 estimates (87.5\%) for Eq. (9). Both equations, being alternative parameterizations, exhibited the same $h$ values for the common parameters $W_{i}$ and $k$ (Table 2). Parameter $k$ showed moderate and severe skewness in $25 \%$ of the estimates. Moderate skewness was observed for parameter $w_{f}$ (Eq. 9) in only $12.5 \%$ of the estimates. Eq. (8) produced more cases in the negligible skewness category than Eq. (9) because parameter $w_{g}$ showed better estimation properties than $w_{f}$.

Median and range values of parameter correlation, RSS and RV of the models are presented in Table 3. The median parameter correlation was smallest for Eqs. (8) \& (9), and largest for the
Richards curve. For RSS and RV, the smallest median values were obtained with the Richards curve, while the largest value of RSS was observed for Eqs. (8) \& (9) and the von Bertalanffy model had the largest median value of RV.
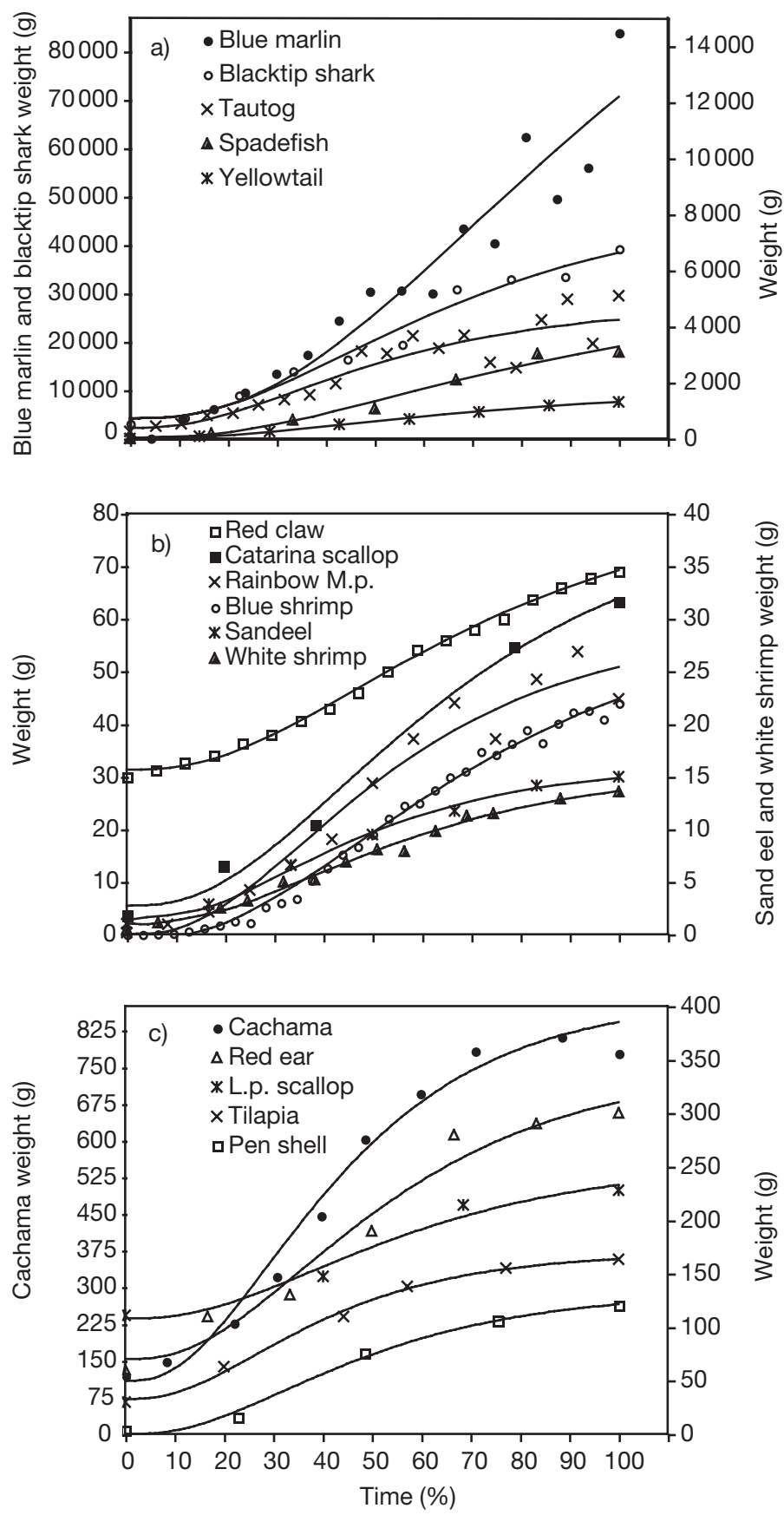

Fig. 2. Fitted growth curves, using Eqs. (8) \& (9), for all the data sets. A common curve for each species is used for both equations, as they gave the same results. The time period analyzed for each species was standardized (percentage) to facilitate representation. M.p. = mother of pearl, L.p. = Lion paw 
Table 2. Absolute values of the Hougaard index of skewness (h) obtained for parameters of the different models and species. See Table 1 for data set abbreviations. U: unable to compute

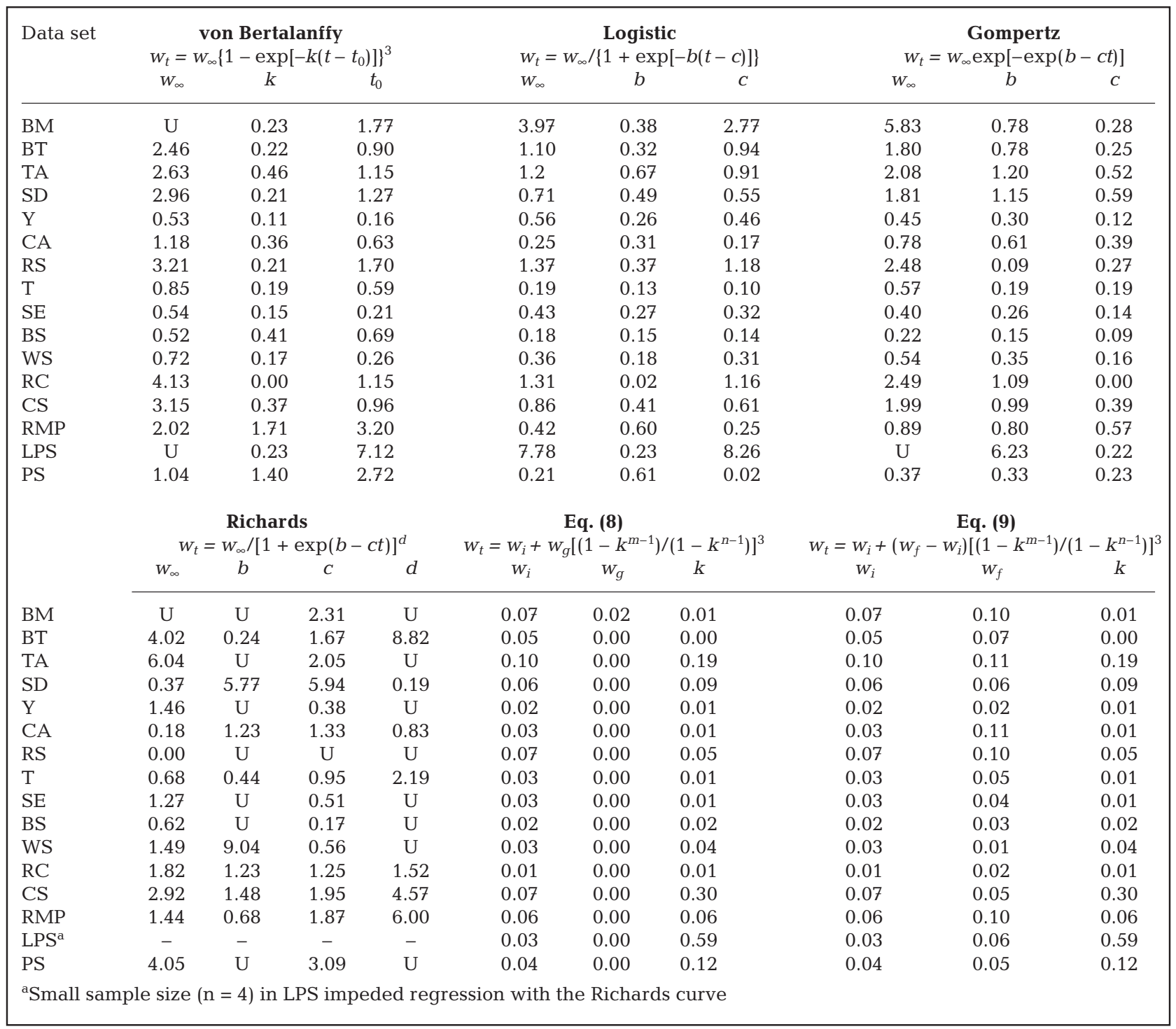

\section{DISCUSSION}

The conventional growth curves exhibited poor statistical properties for estimation, whereas the parameterizations (Eqs. 8 \& 9) of the proposed model presented satisfactory close-to-linear behavior and performed better than the conventional curves. The data sets used in this study corresponded to the growth of several fish, crustacean and molluscs species under a wide variety of situations, thus demonstrating the adaptability of the proposed model. The only situation that produced moderate to severe skewness corresponded to the estimation of $k$ for the lion paw scallop Nodipecten subnodosus, where a very small sample size $(n=4)$ was available for analyzing growth.
Close-to-linear behavior is highly desirable because it allows nonlinear regression procedures to converge easily and to conduct tests for parameter invariance more reliably. Invariance tests are particularly useful when one determines if the parameter values in a model are significantly different between 2 or more data sets. Ratkowsky (1983) gave examples of this test in agricultural research. Hernandez-Llamas et al. (1995) used parameters in Eq. (1) to test for significant differences in growth response of shrimp cultured in ponds, with varying productivity linked to alternative fertilization programs.

Nonlinear estimation procedures require definition of initial values of the parameters to start the convergence process. Obtaining good initial values may be a difficult 
Table 3. Median and range values (within parentheses) of parameter correlation (absolute values), Residual Sum of Squares (RSS) and Residual Variance (RV) obtained from regression analyses conducted with data sets listed in Table 1

\begin{tabular}{|lccc|}
\hline Model & Parameter correlation & RSS & RV \\
\hline von Bertalanffy & $0.93(0.55-0.99)$ & $0.012(0.0009-0.223)$ & $0.0028(0.0002-0.0131)$ \\
Logistic & $0.78(0.21-0.98)$ & $0.010(0.0009-0.232)$ & $0.0017(0.0003-0.0136)$ \\
Gompertz & $0.86(0.07-0.99)$ & $0.013(0.0011-0.224)$ & $0.0024(0.0002-0.0132)$ \\
Richards & $0.94(0.40-0.99)$ & $0.004(0.0007-0.224)$ & $0.0012(0.0002-0.0140)$ \\
Eq. (8) & $0.55(0.00-0.69)$ & $0.015(0.0016-0.224)$ & $0.0024(0.0001-0.0132)$ \\
Eq. (9) & $0.55(0.06-0.71)$ & & \\
a.Eqs. (8) \& (9) gave the same results for RSS and RV & & \\
\hline
\end{tabular}

task. Moreover, regression procedures do not necessarily work in the absence of good initial estimates, which appear to be essential to guarantee convergence (Ratkowsky 1983). Eqs. (8) \& (9) easily converged even when, for example, the initial value $(0.1)$, set by default in STATISTICA, was used for all of the parameters. Alternatively, values for weight gain, initial weight and final weight obtained from the observed data set can be used as reliable initial values for $w_{g}, w_{i}$ and $w_{f}$.

Several parameters of the conventional growth curves correspond to asymptotes and extrapolations. Defining initial values for these parameters was sometimes difficult and their estimators exhibited high skewness. Using asymptotes and extrapolations was particularly inconvenient when the initial weight values in the data sets were far from zero, as was the case for juvenile red claw crayfish Cherax quadricarinatus (Fig. 2b). Under such circumstances, the fitted curves, using the von Bertalanffy, Logistic and Gompertz curves, closely approximated a straight line. An extra parameter in the Richards model allowed some approximation to the sigmoid pattern exhibited by the growth data. Eqs. (8) \& (9), however, resulted in a better description of the sigmoid nature of the growth curve and lower values of RSS and RV, thus supporting our contention that they are good basic models.

Using parameters that correspond to asymptotes and extrapolations in, for example, the von Bertalanffy curve, has been questioned because they lack biological meaning and frequently yield unrealistic estimates (Roff 1980, Schnute \& Fournier 1980). As stated earlier, Urban (2002) reported similar problems when modeling different developmental stages of the pearl oyster Pinctada imbricata.

Parameters $w_{g}, w_{i}$ and $w_{f}$ in Eqs. (8) \& (9) are socalled 'expected-value' parameters. They fall within the observed range of the data and do not correspond to asymptotes or extrapolations. The advantages of 'expected-value' parameters over asymptotic parameters have been emphasized by Ratkowsky (1990). In this study, $w_{i}$ and $w_{g}$ had negligible skewness for all 16 species, $w_{f}$ had negligible skewness for 14 species and moderate skewness for 2 species (Eq. 9), whereas the asymptotic weight $\left(w_{\infty}\right)$ consistently had severe skewness in all data sets for the von Bertalanffy, Logistic and Gompertz curves (Table 2). The poor estimation properties of $w_{\infty}$ were mainly responsible for the nonlinear behavior of these curves.

Ratkowsky (1990) noted that the Richards model presents serious inconveniences because of its intrinsic non-linearity and discouraged its continued use. The results of this study confirm this. Parameters in the Richards model showed higher values of skewness and it was the only one sometimes requiring the use of the Levenberg-Marquardt algorithm, which is more powerful than the Gauss-Newton method, to achieve convergence. The Richards curve was the model where the statistical software most frequently failed to compute $h$ values. It was also the model exhibiting higher correlation values and a major flaw was observed for the data set corresponding to redear sunfish, where correlation values were either 0.0 or 1.0 , and had to be excluded for calculation of median and range values in Table 3.

According to Ratkowsky (1990), judgment on the performance of a model should preferably be based on $\mathrm{RV}$, rather than RSS, which always tends to decrease as extra parameters are added. The value of RV is dependent on the number of parameters used and may increase as parameters are added, if the reduction in the RSS is not sufficient to compensate for the reduction in the number of residual degrees of freedom. The results in this study indicate that there was no overparameterization in the Richards model, which yielded smaller RSS and RV median values. Eqs. (8) \& (9) showed satisfactory statistical performance in terms of parameter correlation and goodness of fit. Both equations had low parameter correlations and yielded satisfactory fits to these data sets.

There are no theoretical or empirical reasons to assume that a model with close-to-linear behavior should necessarily yield smaller or larger parameter correlation, RSS and RV values than a model with nonlinear behavior. Our main objective was to compare the statistical properties for estimation of conventional 
growth curves and a new model. Parameter correlation and goodness-of-fit and parsimony (according to RSS and RV values) were complementary criteria for evaluating model performance. When compared with the conventional curves, the new model showed clear advantages for parameter estimation, lower correlation values and satisfactory fitting to the data sets.

Indiscriminate use of conventional growth curves must be reconsidered for the objective of modeling growth of fishes, crustaceans and molluscs. Their poor statistical behavior clearly suggests that models with close-to-linear properties, as in the proposed model, are better suited to the goal of obtaining good parameter estimation properties. The new model can be used to analyze growth of organisms under a wide variety of situations and to reliably derive statistical inferences on possible relations of its parameters with ecological or management variables.

Acknowledgements. A. Gonzalez originally suggested the need to develop the model. V. Gomez made useful comments on the weight-length relationship. We thank the authors mentioned in Table 1 for providing unpublished data sets. At CIBNOR, I. Fogel provided comments on and corrections to the text.

\section{LITERATURE CITED}

Bardach JE, Ryther J, McLarney WO (1972) Aquaculture: the farming and husbandry of freshwater and marine organisms. John Wiley \& Sons, New York

Bergstad OA, Høines AS, Jørgensen T (2002) Growth of sandeel, Ammodytes marinus, in the northern North Sea and Norwegian coastal waters. Fish Res 56:9-23

Bojorquez G, Lopez G, Meza M (1987) Informe de actividades del proyecto de cultivo inicial de callo de hacha (Pinna rugosa) durante los periodos Septiembre-Diciembre de 1984, Octubre-Diciembre de 1985 y durante EneroDiciembre de 1986 en la Bahía de La Paz, Baja California Sur. Secretaría de Pesca, La Paz, BCS, México

Green BW, Alvarenga HR, Phelps RP, Espinoza J (1989) Honduras: cycle III of the Global Experiment. Pond Dynamics/Aquaculture Collaborative Research Data Reports 6(3), Oregon State University, Corvallis

Haines LM, O'Brien TE, Clarke GPY (2004) Kurtosis and curvature measures for nonlinear regression models. Stat Sinica 14:547-570

Hayse JW (1989) Feeding habits, age, growth and reproduction of Atlantic spadefish Chaetodipterus faber (Pisces: Ephippidae) in South Carolina. Fish Bull 88:67-83

Hernandez-Llamas A, Hernandez-Lizardi JL, GonzalezGaribay M, Magallon-Barajas FJ (1993) Growth and survival response of Penaeus stylirostris to fertilization, pelleted feed and stocking density in earthen ponds. Aquac Fish Manag 24:57-69

Hernandez-Llamas A, Magallon-Barajas FJ, Lechuga-Deveze CH, Bustillos-Guzman JJ, Lopez-Cortés D (1995) Growth potential of wild juvenile Penaeus stylirostris in earthen ponds receiving chemical and organic fertilizers and pelleted feed. Aquac Eng 14(4):317-330
Hostetter EB, Munroe TA (1993) Age, growth, and reproduction of tautog Tautoga onitis (Labridae: Perciformes) from coastal waters of Virginia. Fish Bull 91:45-64

Johns M, Holcomb HW, Hutchins DL, Griffin WL (1981) Summary of shrimp mariculture production data at Texas A\&M University, 1969-1978. TAMU-SG-81-603, College Station, TX

Kiewek NM (2002) Efecto del nivel de lípidos en el desarrollo de juveniles de langosta de agua dulce Cherax quadricarinatus (Von Martens, 1868). BS thesis, Universidad Nacional Autónoma de México

Killam KA, Parsons GR (1989) Age and growth of the blacktip shark, Carcahrhinus limbatus, near Tampa Bay, Florida. Fish Bull 87:845-857

Moreau J, Bambino C, Pauly D (1985) Indices of overall growth performance of 100 tilapia (Cichlidae) populations. In: Maclean JL, Dizon LB, Hosillos LV (eds) The first Asian fisheries forum. Asian Fisheries Society, Manila

Nakada M, Murai T (1991) Yellowtail aquaculture in Japan. In: McVey JP (ed) Handbook of mariculture, Vol. II: Finfish aquaculture. CRC Press, Boca Raton, FL

Pardy CR, Griffin WL, Johns MA, Lawrence AL (1983) A preliminary economic analysis of stocking strategies for penaeid shrimp culture. J World Maricult Soc 14:49-63

Pauly D (1984) Fish population dynamics in tropical waters: a manual for use with programmable calculators. International Center for Living Aquatic Resources Management (ICLARM), Manila

Perez L, Martino G (1989) Análisis microeconómico del cultivo de 'Cachama' (Colossoma sp.) en jaulas flotantes, Guayana, Venezuela. In: Juárez-Palacios R (ed) Avances en el cultivo de peces del genero Colossoma. Proyecto Aquila, Documento de campo No 5. FAO, Brasilia

Prein M (1993) Multivariate analysis of tilapia growth experiments in Israel, Zambia and Peru. In: Prein M, Hulata G, Pauly D (eds) Multivariate analysis in aquaculture research: case studies of tilapias in experimental and commercial systems. International Center for Living Aquatic Resources Management (ICLARM), Manila

Prince ED, Lee DW, Zweifel JR, Brothers EB (1991) Estimating age and growth of young Atlantic blue marlin Makaira nigricans from otolith microstructure. Fish Bull 89:441-459

Ratkowsky D (1983) Nonlinear regression modeling - a unified practical approach. Marcel Dekker, New York

Ratkowsky DA (1986) Statistical properties of alternative parameterizations of the von Bertalanffy growth curve. Can J Fish Aquat Sci 43:742-747

Ratkowsky D (1990) Handbook of nonlinear regression models. Marcel Dekker, New York

Ricker WE (1979) Growth rates and models. In: Hoar WS, Mandall DJ, Brett JR (eds) Fish physiology, Vol VIII. Academic Press, San Diego, CA

Roff DA (1980) A motion for the retirement of the von Bertalanffy function. Can J Fish Aquat Sci 37:127-129

Sadeh A, Pardy CR, Griffin W, Lawrence AL (1986) Uncertainty consideration resulting from temperature variation on growth of Penaeus stylirostris in ponds. Tex J Sci 38(2): 159-172

Schnute J, Fournier D (1980) A new approach to lengthfrequency analysis: growth structure. Can J Fish Aquat Sci 37:1337-1351

Tian X, Leung PS, Hochman E (1993) Shrimp growth functions and their economics implications. Aquac Eng 12: 81-96

Urban HJ (2002) Modeling growth of different developmental stages in bivalves. Mar Ecol Prog Ser 238:109-114 